\title{
Factors underlying migratory bat aggregations in chestnut groves
}

\author{
Susanne Szentkuti ${ }^{1, *}$, Fabio Bontadina ${ }^{1,2 *, * *}$, Martina Spada ${ }^{3}$, Marco Moretti ${ }^{4}$, \\ Nicola Zambelli ${ }^{5}$, Adriano Martinoli ${ }^{3}$, Raphaël Arlettaz ${ }^{1}$ \\ ${ }^{1}$ Institute of Ecology and Evolution, Division of Conservation Biology, University of Bern, Baltzerstrasse 6, 3012 Bern, \\ Switzerland \\ ${ }^{2}$ SWILD, Urban Ecology \& Wildlife Research, Wuhrstrasse 12, 8003 Zurich, Switzerland \\ ${ }^{3}$ Department of Theoretical and Applied Sciences, Università degli Studi dell'Insubria, Via J. H. Dunant 3, 21100 Varese, Italy \\ ${ }^{4}$ WSL Swiss Federal Research Institute, Community Ecology Unit, Via Belsoggiorno 22, 6500 Bellinzona, Switzerland \\ ${ }^{5}$ Centro protezione chirotteri Ticino (CPT), 6714 Semione, Switzerland
}

\begin{abstract}
Deciduous woodlands have undergone major structural changes in Europe in the course of the last century. Dense woodlands have, for instance, replaced traditionally managed, open sweet chestnut groves, and have led to biodiversity losses. Surveys carried out in the southern Alps have shown that the frequency of occurrence of the rare migratory Leisler's bat Nyctalus leisleri in bat boxes is much higher in managed than in unmanaged chestnut groves, pointing to the importance of traditional groves as stopover sites. To identify the reasons for this habitat preference we investigated whether managed chestnut groves constitute a more appropriate foraging ground than closed stands, and whether bat boxes in managed chestnut groves offer more suitable temperature conditions for roosting. Foraging habitat selection and roost usage were investigated by means of radiotracking and temperature loggers, respectively. Foraging Leisler's bats predominantly selected deciduous woodlands over other habitat types, but showed no distinct preference for either type of chestnut grove over other forest types. In managed chestnut groves, bats used cooler boxes than others available in the same habitat, but there was no difference in temperature between the boxes used in managed versus unmanaged groves. Our results provide no evidence that foraging opportunities or roost temperature dictate the forest-specific pattern of bat box occupancy. As an alternative explanation, we suggest that managed chestnut groves may represent optimal lekking arenas due to their open structure and high roost density. Whatever the reason for this habitat preference, partially maintaining traditional management, resulting in a semi-open, mosaic landscape, is likely key to maintaining chestnut groves attractive for this migratory bat.
\end{abstract}

KEY WORDS: Habitat selection · Radiotracking · Open forest stand · Management - Chiroptera . Castanea sativa $\cdot$ Leislers bat $\cdot$ Nyctalus leisleri

\section{INTRODUCTION}

Woodland habitats have undergone major changes both in structure and composition over the past $100 \mathrm{yr}$ throughout Europe (Steele 1975). Historic woodland management practices have been progressively abandoned, a process associated with increased defor- estation, forestry intensification and shrub encroachment. Large areas of natural and traditionally managed woodland have therefore disappeared and have been replaced by dense tree plantations, improved grassland or arable land (Vale 1987).

This is in contrast to the savannah-like forests and groves and orchards, which shaped the traditionally 
used habitats of the European sylvo-pastoral landscape in past centuries. These are characterised by open structures with single mature trees surrounded by a matrix of patches of regularly mowed or grazed unimproved grassland. Such groves and parkland habitats not only have a high cultural and recreational value (Slater 1977), but also act as biodiversity hotspots (Glendell \& Vaughan 2002). They support populations of a variety of threatened species such as the saproxylic long-horned beetle Rosalia alpina (Russo et al. 2011), the dormouse Muscardinus avellanarius (Bright \& Morris 1990), and the forest bat Barbastella barbastellus, which roosts under the loose bark of sun-exposed trees (Russo et al. 2004).

In southern Switzerland the traditionally managed sweet chestnut Castanea sativa groves constitute a particular form of parkland habitat. These stands are semi-natural environments created and maintained by man. They are characterised by the presence of sparse, large old chestnut trees, pruned and grafted to obtain good quality edible fruits. The groves are surrounded by meadows managed by grazing and/or mowing. European chestnut groves currently cover 0.4 million ha of land $(17.7 \%$ of the total chestnutgrowing area worldwide), with $80 \%$ of the area covered by chestnut groves concentrated in Italy and France (Conedera \& Krebs 2008). In southern Switzerland, chestnut groves played an important role in socioeconomic activities until the first part of the twentieth century. Following socioeconomic changes, changes in human food habits, and the spread of chestnut diseases (Conedera \& Krebs $2008)$, the area covered by managed chestnut groves has decreased from 9500 to 3000 ha over the last century (Stierlin \& Ulmer 1999). Abandoned groves quickly become invaded by other tree species and disappear entirely within decades as they evolve into dense mixed forests (Conedera et al. 2000). In a parallel study we found twice the number of bat species (12) and 5 times higher total foraging activity in managed chestnut orchards compared to unmanaged ones, this effect being particularly pronounced in bat species with low flight manoeuvrability (Obrist et al. 2011). Large mature chestnut trees very often have rotten trunks and branches, offering an exceptional variety of cavities (Spada et al. 2008) for many treedwelling species (Moretti et al. 2003, 2004).

The high degree of habitat specialisation in woodland-dwelling bats makes them most vulnerable to habitat deterioration and changes in forest management practices (Safi \& Kerth 2004). Therefore, bats were chosen as an indicator group to study the effect of management of abandoned chestnut groves. A pre- vious bat box investigation (200 boxes in 7 stands over $6 \mathrm{yr}$; Zambelli et al. 2008) showed that managed chestnut groves harboured a higher number of bats than unmanaged, abandoned groves, despite the fact that natural cavities were equally available in both forest types (Spada et al. 2008). Leisler's bat Nyctalus leisleri was the dominant species, representing $97.6 \%$ of the 1684 bats observed. Of 1643 captured Leisler's bats, $92 \%$ were found in bat boxes in managed chestnut groves, although only $75 \%$ of the bat boxes were in this habitat (Zambelli et al. 2008). Previously, this rare species was only occasionally found roosting in other habitats. Thus, chestnut groves, particularly managed ones, seem to be of outstanding importance for this fast-flying and migratory bat (Stebbings 1988).

To explain the unexpected aggregation of Leisler's bats roosting in managed chestnut groves, we tested 2 hypotheses: (1) these bats choose roosts near to optimal foraging habitats and select managed over unmanaged groves because the open space is more attractive for hunting; (2) roosts in managed groves offer more favourable temperature conditions than those in unmanaged groves, because they benefit from the shading provided by the well-developed foliage of ancient, free-standing trees. According to the first hypothesis we expected Leisler's bat to select foraging sites in managed chestnut groves near to the roosts, either because this habitat provides more food (Gruebler et al. 2008) or because it is more accessible to these fast-flying bats with high wing loading (Obrist et al. 2011). According to the second hypothesis, we expected Leisler's bat at these stopover sites to select cooler roosts in managed stands which would enable energy-efficient resting in torpor during the day (e.g. Solick \& Barclay 2006). We tested these predictions by radiotracking Leisler's bats to study foraging habitat selection, and by using data loggers to study roost temperature. The ultimate aim of these observations was to derive management recommendations to support this threatened bat species.

\section{MATERIALS AND METHODS}

\section{Study species}

Leisler's bat is a medium-sized bat (forearm length 40 to $47 \mathrm{~mm}$, body mass 11 to $20 \mathrm{~g}$ ) with the characteristic phenology of a migratory species in temperate regions. By May individuals arrive in their summer areas in northern Europe where they assemble in roosts, such as tree cavities or bat boxes, and form 
summer colonies of mainly breeding females for giving birth. In these colonies, they show a complicated social population structure (Schorcht et al. 2009). Individuals use a large cluster of neighbouring roosts and move, often daily and independently from each other, among roosts (Schorcht 2005). As a consequence, the composition of individuals within roosts changes frequently, similarly to the colonial system called fission-fusion society detected in other treedwelling bats (Kerth et al. 2001, Popa-Lisseanu et al. 2008). Only few adult males are present in summer colonies, and they do not tolerate each other in the same roost. High reproductive output in bats is characteristic for some migratory species and is regarded as an adaptation to the presumed higher mortality in migratory compared to resident bat species. After giving birth, the summer colonies break up in August and the bats migrate over 1000 to $1500 \mathrm{~km}$ towards southwestern Europe (Steffens et al. 2004) where they spend the non-reproductive period, during which mating and hibernation takes place. In the polygynous mating system of Leisler's bats the males monopolise tree cavities, perform song-flights in the vicinity and try to attract females to their roosts in order to build a harem (Helversen \& Helversen 1994).

The main foraging and breeding habitat in Europe is woodland of all types (Schorcht 2002). This species is protected by the Bonn Convention and the European Habitat Directive 92/43/CEE. Leisler's bat is widespread in Ireland but has a patchy distribution in the rest of Europe (McAney \& Fairley 1990), including Switzerland, where it is considered to be scarce (Hausser 1996). According to the IUCN Red List of Threatened Species, Nyctalus leisleri is classified as 'Near Threatened', but there is little data to accurately assess its actual status (Stebbings 1988).

\section{Study area}

The study was conducted in Alto Malcantone, Canton Ticino, Switzerland $\left(46^{\circ} 03^{\prime} \mathrm{N}, 8^{\circ} 53^{\prime} \mathrm{E}\right)$. The area is mountainous, with an altitude ranging from 500 to $1636 \mathrm{~m}$ a.s.l., and extends over $15 \mathrm{~km}^{2}$ (1507 ha). The climate is moist, warm temperate, with rainfall higher in summer (June to September: ca. $200 \mathrm{~mm}$ $\mathrm{m}^{-1}$ ) than in winter (November to February: ca. $100 \mathrm{~mm} \mathrm{~m}^{-1}$ ) (Spinedi \& Isotta 2004). The area is largely covered with woodlands $(67 \%)$. Below $800 \mathrm{~m}$ a.s.l. these are dominated by former coppice stands of European chestnut Castanea sativa, durmast oak Quercus petraea and birch Betula sp., while beech Fagus sylvatica and pastures dominate at higher ele- vations. Traditional chestnut groves account for a low proportion $(10 \%)$ of the woodland area; they cover an area of 400 ha and are mainly found close to villages. Only $25 \%$ of the groves (100 ha) are still traditionally managed or benefit from recent restoration, while the rest (300 ha) have been abandoned and subsequently colonised by dense woody vegetation.

\section{Radiotracking}

Access to Leisler's bats was limited to restricted periods of occurrence in the area. They were abundant in bat boxes from March until the end of May, and from August until the end of October, as determined by checking bat boxes 51 times in the course of $6 \mathrm{yr}$, including 24 checks at regular intervals of 2 wk in the year 2006. In winter only small numbers were present, and in June and July few individuals, all males, were observed. While the spring occurrence peak was dominated by males, females prevailed during the autumn peak (Zambelli et al. 2008). Fieldwork was carried out during these 2 peak periods in 2005 (spring, 14 March-26 May: 8 bats; autumn, 16 August-26 October: 4 bats). We intended to radiotag an equal number of individuals roosting in the 2 grove types; however, the occurrence of the bats was unevenly distributed between the 2 types of grove and our final total of 12 adults comprised 8 from managed and 4 from unmanaged groves, at 6 different groves (4 managed and 2 unmanaged, Table 1). The bats were caught in boxes and measured; while some sub-adult bats were captured, only adults were tagged with BD-2N (0.45 g; Holohil Systems) or BD-2 $(0.62 \mathrm{~g})$ transmitters. The hair between the scapulae was trimmed and the radiotag glued to the skin with surgical cement (SkinBond ${ }^{\circledR}$ ). The tags used did not exceed $6 \%$ of body weight and should therefore not have affected flight manoeuvrability (Aldridge \& Brigham 1988, Bontadina et al. 2002). The hilly area made it extremely challenging to radiotrack the fast flying bats; therefore, we invested up to 9 nights for individual observations (mean: 5 nights). Radiotracking was usually carried out by 2 persons, by car as well as on foot, using 2 Australis 26k scanning receivers (Titley Electronics), an omnidirectional aerial mounted on a car roof, and 3-element yagi antennas. The bats were located during their entire foraging bouts using cross-triangulations performed at 5-min intervals or by 'homing in' (White \& Garrott 1990) on the animal where applicable. The accuracy of locations was classified in the field as high (within a radius of $<50 \mathrm{~m}$ ), medium $(<200 \mathrm{~m})$ 
Table 1. Nyctalus leisleri. Radiotracked Leisler's bats showing, for each individual, sex (F: female; M: male), capture site in a managed (+) or unmanaged (-) chestnut grove, number and accuracy level of radio bearings, and total number of radiotracking nights. 'High' and 'medium' accuracy bearings were estimated to be accurate within a radius $<50$ and $<200 \mathrm{~m}$, respectively

\begin{tabular}{|c|c|c|c|c|c|c|c|}
\hline $\begin{array}{l}\text { Individual } \\
\text { code }\end{array}$ & Sex & Site & Management & $\begin{array}{c}\text { No. of } \\
\text { bearings }\end{array}$ & $\begin{array}{c}\text { High } \\
\text { accuracy }\end{array}$ & $\begin{array}{l}\text { Medium } \\
\text { accuracy }\end{array}$ & $\begin{array}{l}\text { No. of } \\
\text { nights }\end{array}$ \\
\hline 1 & F & Breno & - & 7 & 2 & 5 & 5 \\
\hline 2 & $\mathrm{~F}$ & Mugena & + & 5 & 2 & 3 & 3 \\
\hline 3 & M & Cassina & - & 9 & 0 & 9 & 3 \\
\hline 5 & $\mathrm{~F}$ & Vezio & + & 47 & 2 & 45 & 6 \\
\hline 6 & M & Fescoggia & + & 13 & 2 & 11 & 5 \\
\hline 7 & M & Vezio & + & 19 & 4 & 15 & 4 \\
\hline 8 & $\mathrm{~F}$ & Vezio & + & 29 & 10 & 19 & 6 \\
\hline 9 & $\mathrm{~F}$ & Vezio & + & 28 & 18 & 10 & 5 \\
\hline 10 & M & Vezio & + & 33 & 11 & 22 & 3 \\
\hline 12 & M & Breno & - & 18 & 17 & 1 & 6 \\
\hline 16 & M & Ascigna & + & 29 & 16 & 13 & 9 \\
\hline 17 & $\mathrm{M}$ & Cassina & - & 24 & 24 & 0 & 5 \\
\hline Total & $12: 5 F_{;} 7 \mathrm{M}$ & & & 261 & 108 & 153 & 60 \\
\hline
\end{tabular}

and low $(<500 \mathrm{~m})$, based on previous trials with test transmitters in the area. Only locations of an estimated accuracy of $<200 \mathrm{~m}$ were used for analysis (Table 1), which seems appropriate considering the fast and extensive foraging style of the species. Cross-triangulations result in an estimate of the true location associated with an error polygon (White \& Garrott 1990). An evaluation of the error polygon size in ArcView GIS 3.3 revealed an average diameter of the error polygon of $200 \mathrm{~m}$. All radiotagged individuals were followed to their day roosts in order to assess roost type selection (Spada et al. 2008).

\section{Roost temperature}

We studied temperature variation between 4 different types of roosting sites: used $(\mathrm{m}+)$ and unused $(\mathrm{m}-)$ bat boxes in managed chestnut groves, bat boxes in unmanaged chestnut groves (um-; i.e. exclusively unused boxes due to the low abundance of bats in that habitat), and potential natural roosts in both habitat types (nat). Potentially used, natural roosts were selected in such a way that they showed the same characteristics as natural roosts used by the radiotracked bats (see Table 1 in Spada et al. 2008). A total of 200 bat boxes (type 2F, Schwegler) were installed on trees on the flanks of the main valley in 1999 to 2001 (Zambelli et al. 2008). The bat boxes were positioned randomly on the trees at variable heights between 3 and $5 \mathrm{~m}$, distributed along 5 linear transects in managed ( $\mathrm{n}=151$ boxes), and 2 transects in unmanaged chestnut groves ( $\mathrm{n}=49$ boxes). Bat boxes were defined as 'used' and 'unused' on the ba- sis of bats observed in the $6 \mathrm{yr}$ preceding our study (1999 to 2004, n = 27 controls; Zambelli et al. 2008). Entrance holes to boxes classified as unused were blocked with a piece of loose fabric to prevent bats or any other animals from using the boxes and thereby altering box internal temperature. A previous test revealed no temperature differences caused by the fabric (data not shown). Natural roost sites were chosen randomly, within the 7 chestnut groves, from among the potential roosts that were considered as having a suitable configuration according to data gathered from radiotracked individuals using natural roosts (details in Spada et al. 2008). A total of 53 data loggers (TinyTalks, TK-0014, Gemini; and i-buttons, DS1921G-F5, Maxim Integrated Products) were distributed as equally as possible among the 4 roost types. Hourly temperature measurements were collected during the seasons with bat presence in 2005 . Additionally, we measured roost exposure (aspect) as well as the degree of canopy cover at roost height, i.e. uncovered $(<25 \%)$, half-covered ( 25 to $75 \%$ ) and highly covered $(>75 \%)$.

\section{Statistical analyses}

\section{Foraging habitat selection}

This species exhibits an opportunistic foraging behaviour: the bats are constantly in fast flight over extended areas. When listening to their ultrasound, feeding buzzes can occasionally be heard, without indicating a spatial accumulation of the bats in small foraging patches. Therefore, we assumed all flight activ- 
ity to be foraging behaviour. Habitat selection was investigated first by compositional analysis, which uses individuals as units and compares use of resources with availability within an animal's activity range (Aebischer et al. 1993). An individual's activity range, in clear distinction to the 'home range', includes the total area used by an animal during the short study period. For each individual, the activity range was determined as the $100 \%$ minimum convex polygon (MCP) drawn from all the recorded locations. We used this approach because the many areas without observed locations, but possibly accessible to an individual, are better represented by a polygon. Additionally Bingham et al. (2010) showed that compositional analysis, based on percentages of occurrence in habitats, performs better than an analysis based on Euclidean distance to the nearest habitat. We defined a $200 \mathrm{~m}$ buffer zone around all locations in accordance with the average location error of radiotracking data (see 'Radiotracking' above) (Harris et al. 1990, Bontadina \& NaefDaenzer 1996). Core foraging areas were calculated from the $50 \%$ kernel estimate of the utilisation distribution (Worton 1989); the smoothing factor $h$ was set to $200 \mathrm{~m}$ according to the same average location error (Bontadina \& Naef-Daenzer 1996, Bontadina et al. 2002). The first locations of emerging bats were not recorded in order not to overestimate the vicinity of the roosts. Eight habitat types were identified based on data from the Forest Department of the Canton of Ticino in southern Switzerland: (1) deciduous woodland (with $<20 \%$ chestnut trees); (2) deciduous woodland with $\geq 20 \%$ chestnut trees; (3) managed chestnut grove; (4) unmanaged chestnut grove; (5) riparian woodland; (6) coniferous woodland; (7) pasture, and (8) settlement. Compositional analysis with Wald $\chi^{2}$ statistics was performed using the Excel macro Compos Analysis 4.1 (Smith 2005), applying randomisation with 1000 iterations, as recommended by Aebischer et al. (1993). In order to test main habitat categories, we first grouped all the deciduous woodland types (1 to 5, above) and used 4 main habitat categories 'deciduous forests', 'coniferous woodlands', 'pastures', and 'settlements' in the compositional analysis to test for selection by comparing the visited habitats present in the $50 \%$ core of an individual's foraging area to the proportion of available habitats within each individual's MCP. In a second step, we split deciduous forests into the 5 types above ( 1 to 5); however, compositional analysis was not robust enough, due to the presence of too many empty cells. For a representation of the intensity of selection of the single habitat types, we therefore calculated the Jacobs' (1974) preference in$\operatorname{dex}(J)$ according to the following formula:

$$
J=(u-a) /[(u+a)-2 u a]
$$

where $u$ is the proportion of used and a the proportion of available habitat types. This index ranges from -1 , for maximum negative selection (avoidance), to +1 for maximum positive selection. Statistical significance of deviations from zero in the sample was calculated by applying $t$-tests where the null hypothesis corresponds to a Jacobs' index equal to zero.

To exclude possible confounding effects on foraging habitat selection, we tested 2 variables related to attractive habitat elements. We compared the 2 continuous variables 'distance to nearest watercourse' (water and productive food source) and 'distance to nearest artificial streetlight' (abundant food source), at both actual locations and a similar number of points drawn at random from within each individual activity range. For that purpose, ANOVAs were performed on square-root transformed data to comply with restrictions regarding variable normality and homoscedasticity.

\section{Roost temperature}

The 2 dependent parameters daily mean roost temperature (average of hourly temperatures) and mean delta roost temperature (maximum day temperature minus minimum day temperature) were calculated for each roost. We only considered temperature data obtained from 06:00 until 18:00 h, approximately the daylight period, because bats roost in boxes mainly during daylight time. Since a strong positive correlation existed between these 2 parameters (spring: Spearman rank correlation $r_{S}=0.68, n=53, p<0.001$; autumn: $r_{S}=0.72, n=53, p<0.001$ ), only mean daily roost temperature was used in further analyses.

Combining the temperature data collected in spring and autumn we compared thermal conditions within roosts between the 4 different types of roosting sites mentioned above $(\mathrm{m}+, \mathrm{m}-$, um-, nat) using ANOVAs, with mean daily roost temperature as the dependent variable. Independent variables were roost type, aspect (in 8 classes of $45^{\circ}$ ), degree of canopy cover (uncovered, half-covered, highly covered as described above), site (study plot) and season (spring; autumn). Tukey-Kramer Honestly Significant Difference (HSD) post hoc tests were used for pairwise comparisons. All variables were tested for normality and variance homogeneity, and square transformed when necessary, prior to running ANOVAs. We used JMP Version 4 as the statistical package (SAS Institute) for the analyses. 


\section{RESULTS}

\section{Foraging habitat selection analysis}

We collected 261 locations during a total of 60 radiotracking nights with 12 radiotagged individuals (n = 8 in spring, 4 in autumn; 7 males and 5 females; Table 1).

The MCP encompassing the activity ranges of all radiotracked bat individuals had a total area of 12137 ha. Individual activity ranges (MCP areas) were $1501 \pm 1869$ ha (mean \pm SD), and ranged from 133 to 6668 ha, thus showing strong individual variation (Table 2). Activity range areas did not reach an asymptotic plateau with the number of locations collected; consequently they represent minimum estimates. The mean distance flown during 1 night between the most distant location and the previous day roost was $1969 \pm 1754 \mathrm{~m}$, and the maximum distance flown was $13614 \mathrm{~m}$ (Table 2). Mean core foraging area revealed by $50 \%$ kernel density estimates was $43.7 \pm 41.3$ ha, ranging from 16.8 to 131 ha.

The habitat categories present in the area depicted as available (MCP of all radio-tracked individuals) were deciduous woodlands with a predominance of chestnut trees $(36 \%)$, pastures $(23.1 \%)$, deciduous woodlands where chestnut trees did not predominate $(22 \%)$, settlements $(15.4 \%)$, unmanaged chestnut groves $(1.6 \%)$, coniferous woodlands $(1.4 \%)$, man-

Table 2. Nyctalus leisleri. Activity range size of individual radiotracked Leisler's bats, nightly mean $( \pm \mathrm{SE})$ distance travelled and maximum distance between the most distant location and the previous roost. Range size was calculated for each individual as the $100 \%$ minimum convex polygon (MCP) drawn from all recorded locations

\begin{tabular}{|lccc|}
\hline $\begin{array}{l}\text { Individual } \\
\text { code }\end{array}$ & $\begin{array}{c}\text { Activity range } \\
\text { (MCP) }(\mathrm{ha})\end{array}$ & $\begin{array}{c}\text { Mean distance } \\
\pm \mathrm{SE}(\mathrm{m})\end{array}$ & $\begin{array}{c}\text { Maximum } \\
\text { distance }(\mathrm{m})\end{array}$ \\
\hline 1 & 222 & $472 \pm 301$ & 1080 \\
2 & 337 & $582 \pm 1758$ & 3553 \\
3 & 133 & $748 \pm 408$ & 1338 \\
5 & 2697 & $5693 \pm 1284$ & 8109 \\
6 & 199 & $728 \pm 352$ & 1514 \\
7 & 2131 & $2020 \pm 1693$ & 5165 \\
8 & 1108 & $2107 \pm 965$ & 4743 \\
9 & 1814 & $3405 \pm 1988$ & 6538 \\
10 & 2054 & $4266 \pm 2393$ & 7107 \\
12 & 432 & $591 \pm 450$ & 1730 \\
16 & 6668 & $2754 \pm 4635$ & 13614 \\
17 & 216 & $258 \pm 363$ & 1647 \\
& 12137 & $1969 \pm 1754$ & $4678 \pm 1082$ \\
& (Total area) & (Mean $\pm \mathrm{SE})$ & (Mean $\pm \mathrm{SE})$ \\
\hline
\end{tabular}

aged chestnut groves $(0.3 \%)$ and riparian woodland $(0.25 \%)$. The compositional analysis of the 4 main habitat categories revealed that Leisler's bats significantly selected deciduous forests over pasture, coniferous woodlands and settlements (Wald $\chi^{2}=21.06$, $\mathrm{df}=3$, randomised $\mathrm{p}=0.006$; Fig. 1).

When the 8 habitat categories were analysed in detail, Jacobs' indices for habitat preferences confirmed the pattern found in the compositional analysis, with positive indices for managed and 'unmanaged chestnut groves and deciduous woodlands' contrasting with negative indices for the other habitats (Fig. 2). Finally, Leisler's bats did not select their foraging areas either with respect to the distance to watercourses or to the distance to artificial streetlights (ANOVA, $F_{1,521}=0.0015, \mathrm{p}=0.97$ and $F_{1,521}=$ $0.0012, \mathrm{p}=0.97$, respectively).

\section{Roost temperature}

The temperature at 53 roosts showed that season was the factor which accounted for most of the variation, with autumn temperatures being significantly higher than spring temperatures (season effect $F_{1,846}$ $=30.6, \mathrm{p}<0.001$; Tukey-Kramer HSD, $\mathrm{p}<0.05)$. Additionally, the following factors were significant: roost type $\left(F_{3,844}=15.4, \mathrm{p}<0.001\right)$, canopy cover $\left(F_{2,845}=7.89, \mathrm{p}<0.001\right)$ and study plot $\left(F_{52,795}=5.62\right.$, $\mathrm{p}<0.001)$. Post hoc tests indicated that natural roosts

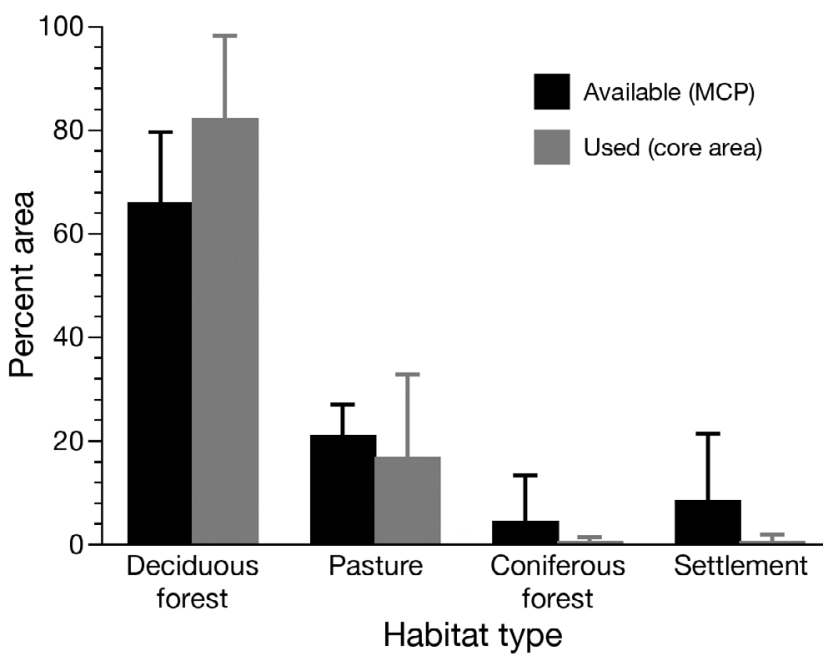

Fig. 1. Nyctalus leisleri. Pattern of habitat selection in 7 male and 5 female Leisler's bats: mean (+SE) activity range size, calculated for each individual as the $100 \%$ minimum convex polygon (MCP) drawn from all recorded locations, and habitat used within this range (i.e. the $50 \%$ core foraging area). Compositional analysis revealed a significant selection for deciduous forest over the other 3 habitats $(p<0.01)$ 


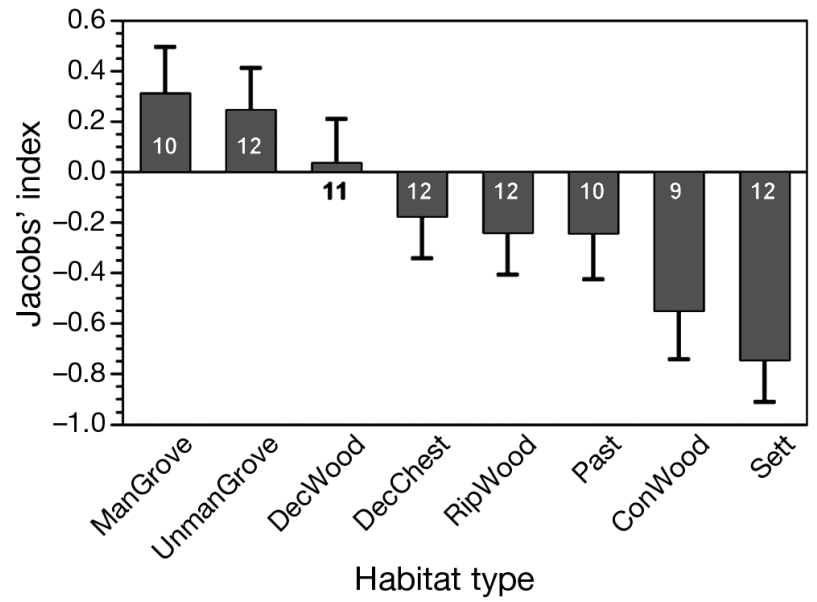

Fig. 2. Nyctalus leisleri. Jacobs' indices (mean $+\mathrm{SE})$ for habitat selection by Leisler's bats averaged over individuals. Values within or beneath the bars are sample size. Positive and negative values indicate positive and negative selection, respectively. ManGrove: managed chestnut groves; UnmanGrove: unmanaged chestnut groves; DecWood: deciduous woodland without predominance of chestnut trees; DecChest: deciduous woodland with predominance of chestnut trees; RipWood: riparian woodland; Past: pasture; ConWood: coniferous woodland; Sett: settlements

had significantly lower temperatures than all other roost types (Tukey-Kramer HSD, $\mathrm{p}<0.05$ ). There was a significant negative influence of canopy cover on roost temperature: the daily roost temperature at highly covered roosts was significantly lower compared to roost temperature at half-covered and uncovered sites (mean \pm SE: $13.55 \pm 0.27^{\circ} \mathrm{C}$, vs. 14.66 $\pm 0.28{ }^{\circ} \mathrm{C}$ and $15.29 \pm 0.39{ }^{\circ} \mathrm{C}$, respectively; TukeyKramer HSD, $p<0.05)$. There was no significant difference between the temperatures measured in boxes in unmanaged chestnut groves (um-) and used boxes in managed chestnut groves $(\mathrm{m}+)$ (Fig. 3), which did not support our hypothesis that roost climatic conditions may explain patterns of habitat occupancy.

\section{DISCUSSION}

The aggregation of hundreds of individuals of a usually rare species, the Leisler's bat, raised the question: Which ecological factors determine their presence in mainly managed, old chestnut groves to the south of the Alps? We showed that foraging Leisler's bats positively selected deciduous woodlands over coniferous woodlands, pastures and settlements. They did not use deciduous woodlands adjacent to their roosts, but used more distant sites (mean foraging distance about $2 \mathrm{~km}$ ). Chestnut groves seemed to be preferred for foraging regardless of their management. Since we were able to exclude a confounding influence of watercourse and streetlight, 2 features related to abundant insect provision (e.g. Rydell 1994, Glendell \& Vaughan 2002), these results demonstrate the importance of deciduous woodlands, including chestnut groves, as foraging areas in the study region. Although managed and unmanaged chestnut groves made up only 0.3 and $1.6 \%$ of the available study area, respectively, they each represented habitat in which $9 \%$ (in total $18 \%$ of 261 locations) of foraging activity occurred. Because forests in the study area have not been managed for $60 \mathrm{yr}$, abandoned chestnut groves are composed of a mix of tree species, with a structure that is relatively homogeneous and fairly comparable to other deciduous woodlands. The main differences between abandoned chestnut groves and other deciduous woodland are, firstly, the mosaic pattern of chestnut groves that derives from interspersed managed and unmanaged groves and, secondly, the characteristic presence of scattered mature trees, a configuration which may actually be the cause of the special attractiveness for Leisler's bat. Interestingly, open stands of sweet chestnut woodlands are also a preferred foraging habitat of Leisler's bat in the southern Apennines, Italy (Russo \& Jones 2003), suggesting a general, geographically widespread preference. Preliminary research also indicates a particular

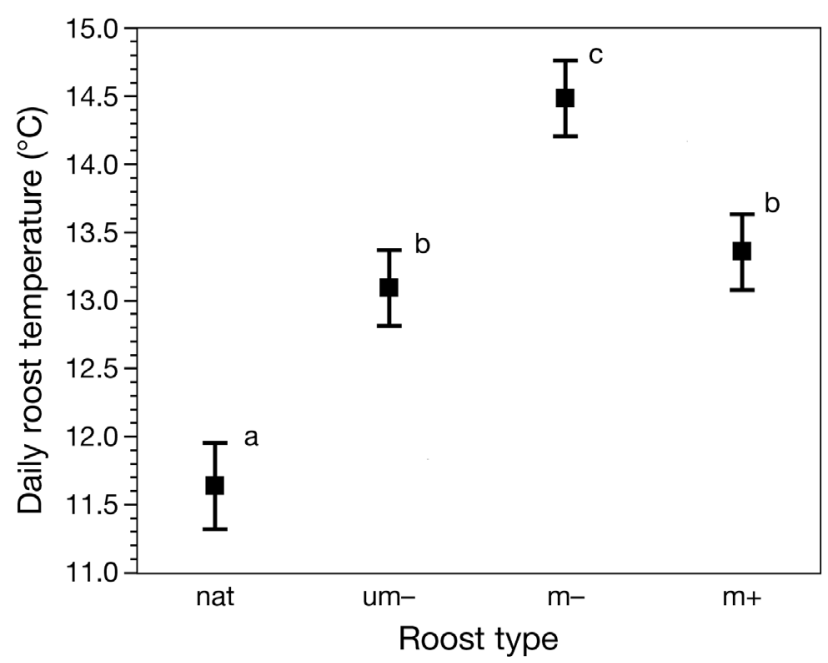

Fig. 3. Nyctalus leisleri. Mean $( \pm \mathrm{SE})$ daily roost temperature $\left({ }^{\circ} \mathrm{C}\right)$ of Leisler's bats with respect to roost type. Different letters indicate significant differences between pairs $(p<0.05$, Tukey-Kramer post hoc pairwise comparisons). Roost types, in relation to management of chestnut groves and use by bats: nat: natural roost sites in both habitat types, unknown usage; um-: unmanaged, unused; m-: managed, unused; $\mathrm{m}+$ : managed, used; 
importance of mature chestnut trees for birds and insects: Python \& Moretti (2007) found a total of 57 bird species in chestnut groves (mean $\pm \mathrm{SD}$ : $16 \pm 3.1$ vs. $14 \pm 2.0$ in managed and unmanaged groves, respectively). Since there is no evidence for a lower availability of natural cavities in managed versus unmanaged chestnut groves (Spada et al. 2008) and the relative density of bat boxes per area was kept constant, the high occupancy of bat boxes in open, managed stands (Zambelli et al. 2008) indeed seems to be related to a higher bat concentration in that habitat. What may then explain this preference for roosting in managed chestnut groves? Our data show that used bat boxes in managed chestnut groves have cooler temperatures than unused bat boxes. This preference for cooler roosts may be explained by physiological constraints. In spring and autumn, bats regularly undergo daily torpor to save energy for thermoregulation. It has been shown that roost tree and site characteristics selected by female bats vary with the stage of reproduction (e.g. Lausen \& Barclay 2002, Garroway \& Broders 2008); in spring and autumn bats prefer cooler temperatures that facilitate entry into torpor and reduce energetic costs. In contrast, lactating females select warm roosts (Kerth et al. 2001). However, Leisler's bats do not give birth in our study area; this area serves some individuals as a stopover site during migration, whereas for others it appears to provide a transitional seasonal habitat where mating occurs (Zambelli et al. 2008, S. Giavi et al. unpubl. data).

We showed that the density of canopy influenced the temperature within bat boxes, with a denser canopy shading the roost and resulting in lower box temperature. Our results also show that natural roosts had even lower temperatures than the bat boxes. Combining these findings with the criteria for selection of natural roosts by Leisler's bats in the study area (28 of 40 roosts were in trees i.e. in large viable chestnut trees in open groves; Spada et al. 2008), we suggest that optimal forestry practices would support a dense canopy around free standing, large hollow trees to enhance thermal conditions in cavities for non-breeding populations, and that bat boxes for this species should be installed in the shade of tree canopies.

Since our data suggests that neither the management regime of chestnut groves, nor roost availability or roost temperature explain the aggregations of roosting bats in managed chestnut groves, the question remains: What are the reasons for the observed pattern? We suggest that this pattern is triggered by social factors related to the mating behaviour of the species that can be primarily explained by flight constraints. With their long, narrow wings (relatively small wing area and high wing loading), Leisler's bats are among the fastest-flying bats (Obrist et al. 2011), a trait possibly crucial for long-distance migration and foraging, which however dramatically reduces flight manoeuvrability. During the courtship season, constraints in manoeuvrability might prove a limitation when Leisler's bat males engage in display flights to attract mates to their roosts. These display flights are performed close to mating roosts where males tend to attract females in order to form their periodic harems (Dondini \& Vergari 2009). Males are also known to call for females from the roost entrance (Helversen \& Helversen 1994, Furmankiewicz et al. 2011); in the latter case, an aggregation of roosts plays the role of a lek mating arena. Males would therefore be expected to select roosts with high accessibility (Ohlendorf \& Ohlendorf 1998), such as our bat boxes in managed chestnut groves, whilst boxes hung up in cluttered conditions (e.g. dense, unmanaged groves) would be avoided. In another fast flying species, the North American bat Lasiurus cinereus, open flyways to roosts were also identified as a major criterion for roost selection (Klug et al. 2012). The finding that forest structure is a key factor is also supported by the result that there was no significant difference in bat box temperature between the used roosts in managed stands and unused roosts in the denser, unmanaged stands (Fig. 3). Furthermore, in autumn and early spring, bat boxes in managed stands were occupied by single males together with few females, indicating harems, where mating occurs (N. Zambelli et al. unpubl.). An alternative explanation would be that male 'advertisement calls' may travel farther, resulting in a more effective courtship behaviour (D. Russo pers. comm.), a hypothesis which could be tested experimentally, e.g. by playback experiments.

In conclusion, we suggest that bat aggregations in managed chestnut groves are not triggered principally by an ecological ambient factor but rather by a social factor. The availability of roosts combined with the semi-open structure of the managed chestnut groves makes them an optimal habitat during mating season. Old chestnut groves, characterised by widely spaced mature trees, and partially managed in traditional style, result in mosaic landscapes, which are likely of prime importance for the persistence of Leisler's bat populations.

Our results on the habitat selection by Leisler's bats suggest (1) that deciduous woodlands may constitute important foraging habitats for Leisler's bats 
in continental Europe, and (2) that a mosaic of unmanaged and managed chestnut groves might provide optimal mating habitats. The present study suggests that particularly open chestnut groves play an important role as stopover habitats, possibly crucial for this long-distance migrant bat that covers over $1000 \mathrm{~km}$ from the nursery roosts in northeastern Europe to the wintering grounds in southwestern Europe (Ohlendorf et al. 2001). This study demonstrates how a dependence on specific roosting habitat, due to flight and behavioural constraints, makes a mobile species vulnerable to alterations in woodland structure. In this context, the widespread abandonment of various traditional woodland management practices has reduced habitat diversity and has probably negatively affected the status of Leisler's bat in continental Europe. Thus, the management of restored patches within the abandoned chestnut groves would need to be resumed in order to shape a habitat matrix to support this potentially vulnerable tree-dwelling species.

Acknowledgements. This study is part of the SELPI (SELve \& PIpistrelli) research programme which was supported by the Forest Department of the Canton of Ticino, Switzerland, and by a grant from the Hochschulstiftung of the University of Bern. We thank Stefania Bologna, Francesca Sozzi, Sara Valoroso and all other people involved in field work, the community of Breno for their support and the city of Lugano for providing the field station. We are grateful to Marzia Mattei-Roesli (Centro protezione chirotteri Ticino), Marco Conedera (Insubric Ecosystems, WSL), Wigbert Schorcht, Danilo Russo and 2 anonymous reviewers who made useful comments that helped us improve previous drafts of the manuscript. The study was conducted under licence from the nature conservation administration of the Canton of Ticino issued on 24 February 2005.

\section{LITERATURE CITED}

Aebischer NJ, Robertson PA, Kenward RE (1993) Compositional analysis of habitat use from animal radio-tracking data. Ecology 74:1313-1325

Aldridge HDJN, Brigham RM (1988) Load carrying and manoeuvrability in an insectivorous bat: a test of the $5 \%$ "rule" of radio-telemetry. J Mammal 69:379-382

Bingham RL, Brennan LA, Ballard BM (2010) Discrepancies between Euclidean distance and compositional analyses of resource selection data with known parameters. J Wildl Manag 74:582-587

Bontadina F, Naef-Daenzer B (1996) Analysing spatial data of different accuracy: the case of greater horseshoe bats foraging. In: Le Maho Y (ed) Wildlife-Biotelemetry. CNRS-CEPE, Strasbourg. www.rhinolophus.net/wild tele.pdf

Bontadina F, Schofield H, Naef-Daenzer B (2002) Radiotracking reveals that lesser horseshoe bats (Rhinolophus hipposideros) forage in woodland. J Zool (Lond) 258: 281-290
Bright PW, Morris PA (1990) Habitat requirements of dormice Muscardinus avellanarius in relation to woodland management in southwest England. Biol Conserv 54:307-326

Conedera M, Krebs P (2008) History, present situation and perspective of chestnut cultivation in Europe. In: Abreu CG, Peixoto FP, Gomes-Laranjo J (eds) Proc 2nd Iberian Chestnut Congress, Vila Real, 20-22 Feb 2007. Acta Hortic 784:23-27

Conedera M, Stanga P, Lischer C, Stöckli V (2000) Competition and dynamics in abandoned chestnut orchards in southern Switzerland. Ecologia Mediterranea 26: $101-112$

Dondini G, Vergari S (2009) Harem size and male mating tactics in Nyctalus leisleri (Kuhl, 1817) (Chiroptera, Vespertilionidae). Hystrix 20:147-154

Furmankiewicz J, Ruczynski I, Urban R, Jones G (2011) Social calls provide tree-dwelling bats with information about the location of conspecifics at roosts. Ethology 117 : 480-489

Garroway CJ, Broders HG (2008) Day roost characteristics of northern long-eared bats (Myotis septentrionalis) in relation to female reproductive status. Ecoscience 15: 89-93

Glendell M, Vaughan N (2002) Foraging activity of bats in historic landscape parks in relation to habitat composition and park management. Anim Conserv 5:309-316

> Gruebler M, Morand M, Naef-Daenzer B (2008) A predictive model of the density of airborne insects in agricultural environments. Agric Ecosyst Environ 123:75-80

Harris S, Cresswell WJ, Forde PG, Trewhella WJ, Woollard T, Wray S (1990) Home-range analysis using radio-tracking data: a review of problems and techniques particularly as applied to the study of mammals. Mammal Rev 20:97-123

Hausser J (1996) Säugetiere der Schweiz: Verbreitung, Biologie, Ökologie. Birkhäuser, Berlin

Helversen O, Helversen D (1994) The 'advertisement song' of the lesser noctule bat (Nyctalus leisleri). Folia Zool (Brno) 43:331-338

Jacobs J (1974) Quantitative measurement of food selection. Oecologia 14:413-417

> Kerth G, Weissmann K, König B (2001) Day roost selection in female Bechstein's bat (Myotis bechsteinii): a field experiment to determine the influence of roost temperature. Oecologia 126:1-9

Klug BJ, Goldsmith DA, Barclay RMR (2012) Roost selection by the solitary, foliage-roosting hoary bat (Lasiurus cinereus) during lactation. Can J Zool 90:329-336

> Lausen CL, Barclay RMR (2002) Roosting behaviour and roost selection of female big brown bats (Eptesicus fuscus) roosting in rock crevices in southeastern Alberta. Can J Zool 80:1069-1076

McAney C, Fairley J (1990) Activity of Leisler's bat Nyctalus leisleri at a summer roost in Ireland. Myotis 28:83-91

Moretti M, Roesli M, Gamboni AS, Maddalena T (2003) I pipistrelli del Cantone Ticino. Mem Soc Ticinese di Scienze Naturali 6:1-9

Moretti M, Tonolla D, Altenburger I, Duelli P (2004) Biodiversità delle selve castanili del Monte Grand (Soazza, Grigioni). Quad Grigioni Ital 73:355-362

Obrist MK, Rathey E, Bontadina F, Martinoli A, Conedera M, Christe P, Moretti M (2011) Response of bat species to sylvo-pastoral abandonment. For Ecol Manag 261: 789-798 
Ohlendorf B, Ohlendorf L (1998) Zur Wahl der Paarungsquartiere und zur Struktur der Haremsgesellschaften des Kleinen Abendseglers (Nyctalus leisleri) in SachsenAnhalt. Nyctalus 6:476-491

Ohlendorf B, Hecht B, Strassburg D, Theiler A, Agirre Mendi PT (2001) Bedeutende Migrationsleistung eines markierten Kleinabendseglers (Nyctalus leisleri): DeutschlandSpanien-Deutschland. Nyctalus 8:60-64

Popa Lisseanu A, Bontadina F, Mora O, Ibanez C (2008) Highly structured fission-fusion societies in an aerialhawking, carnivorous bat. Anim Behav 75:471-482

Python A, Moretti M (2007) L'avifauna delle selve castanili. Progetto di ricerca sull'effetto dell'abbandono e del recupero delle selve nella Svizzera italiana. Ficedula 1:5-10

Russo D, Jones G (2003) Use of foraging habitats by bats in a Mediterranean area determined by acoustic surveys: conservation implications. Ecography 26:197-209

Russo D, Cistrone L, Jones G, Mazzoleni S (2004) Roost selection by barbastelle bats (Barbastella barbastellus, Chiroptera: Vespertilionidae) in beech woodlands of central Italy: consequences for conservation. Biol Conserv 117:73-81

Russo D, Cistrone L, Garonna AP (2011) Habitat selection by the highly endangered long-horned beetle Rosalia alpina in southern Europe: a multiple spatial scale assessment. J Insect Conserv 15:685-693

Rydell J (1991) Seasonal use of illuminated areas by foraging northern bats Eptesicus nilssonii. Holarct Ecol 14: 203-207

Safi K, Kerth G (2004) A comparative analysis of specialization and extinction risk in temperate-zone bats. Conserv Biol 18:1293-1303

Schorcht W (2002) Zum nächtlichen Verhalten von Nyctalus leisleri (Kuhl 1817). Schriftenr Landschaftspflege Naturschutz 71:141-161

Schorcht W (2005) Zur Phänologie des Kleinabendseglers, Nyctalus leisleri (Kuhl, 1817), in Südthüringen. Nyctalus 10:351-353

Schorcht W, Bontadina F, Schaub M (2009) Variation of adult survival drives population dynamics in a migrating forest bat. J Anim Ecol 78:1182-1190

Editorial responsibility: Steven Rossiter,

London, UK
Slater TR (1977) Landscape parks and the form of small towns in Great Britain. Trans Inst Br Geogr 2:314-331

Smith PG (2005) Compos Analysis version 4.1 user's guide. Program Version 4.1. Smith Ecology, Abergavenny. www.smithecology.com/software.htm

Solick DI, Barclay RMR (2006) Thermoregulation and roosting behaviour of reproductive and nonreproductive female western long-eared bats (Myotis evotis) in the Rocky Mountains of Alberta. Can J Zool 84: 589-599

Spada M, Szentkuti S, Zambelli N, Mattei-Roesli M and others (2008) Roost selection by non-breeding Leisler's bats in montane woodlands: implications for habitat management. Acta Chiropt 10:81-88

Spinedi F, Isotta F (2004) Il clima del Ticino. Dati Statistiche Società 6:4-39

Stebbings RE (1988) Conservation of European bats. Christopher Helm, London

Steele RC (1975) Forests and wildlife. Philos Trans R Soc B 271:163-178

Steffens R, Zöphel U, Brockmann D (2004) 40th anniversary Bat Marking Centre Dresden - evaluation of methods and overview of results. Sächsisches Landesamt für Umwelt und Geologie, Dresden

Stierlin HR, Ulmer U (1999) Forest structure. In: Brassel P, Brändli UB (Eds) Results of the Second Swiss National Forest Inventory 1993-1995. Swiss Federal Research Institute WSL, Birmensdorf, p 103-150

Vale TR (1987) Vegetation change and park purposes in the high elevations of Yosemite National Park, California. Ann Assoc Am Geogr 77:1-18

White GC, Garrott RA (1990) Analysis of wildlife radiotracking data. Academic Press, San Diego, CA

Worton BJ (1989) Kernel methods for estimating the utilization distribution in home-range studies. Ecology 70 : $164-168$

Zambelli N, Mattei-Roesli M, Moretti M (2008) Nottola di Leisler (Nyctalus leisleri, Chiroptera), regina delle selve castanili. Resoconto dopo 6 anni di monitoraggio di 200 cassette-nido. Boll Soc Ticinese di Scienze Naturali 96: $49-59$

Submitted: June 6, 2012; Accepted: January 23, 2013 Proofs received from author(s): June 24, 2013 